BY

\author{
WILLIAM G. CLAPP \\ WEBER STATE UNIVERSITY \\ SCHOOL OF TECHNOLOGY \\ ELECTRONIC ENGINEERING TECHNOLOGY \\ OGDEN, UTAH 84408-1703 \\ $801-626-7097$
}

FOR

AIAA/UTAH STATE UNIVERSITY CONFERENCE ON SMALL SATELLITES

AUGUST 3,1990 


\title{
ASTRONAUT DEPLOYABLE SATELLITE
}

\author{
William G. Clapp
}

The Astronaut Deployable Satellite (ADSAT) is an educational satellite being designed and built by faculty, local engineers, and students at Weber State University. The ADSAT is our third satellite project after the success of two others, NUSAT I (ChallengerApril 85) and WEBERSAT-OSCAR 18 (Arisne-Jan 90. The ADSAT is designed to be tossed into space by an astronaut. The 16" $\times 16^{\prime \prime} \times 4^{\prime \prime}$ ADSAT is self-contained and is designed to ride into space in a mid-deck stowage locker on the shuttle. When launch is desired, the astronaut removes the ADSAT from the locker and carries it outside. The astronaut then deploys the antennas and throws the ADSAT into space.

The ADSAT is designed to send to Earth voice messages concerning onboard experiments. The volce messages will be generated by an onboard speech synthesizer that verbally relays the data to low-cost scanners on the ground. ADSAT is being designed to be thrown in a couple of years if NASA will agree to the concept.

\section{INTRODUCTION}

Realistic engineering training at the university level is a difficult task to accomplish successfully. There is no substitute for on-the-job training that takes place after graduation. Many universities offer senior projects courses in undergraduate programs to help the student transition into their entry-level engineering positions. The School of Technology at Weber State University has implemented a rigorous one-year senior projects program that consumes about 300 hours for each student. The students must work in teams to accomplish a significant task. A satellite is an ideal project because it can be a well defined complete system. A satellite does not take up much storage space during construction and can be put into orbit to eliminate long-term storage problems.

\section{HISTORY}

Weber State University faculty, local engineers, and students have been building satellites since 1978. The first satellite, NUSAT $I$, was a joint project between Weber State University and Utah State University. NUSAT I was inserted into orbit in April of 1985, from the Shuttle Challenger. Over 
1500 two-way communications were completed during its 20 month life before reentry. Its mission to calibrate FAA radars throughout the world was not totally accomplished because of the unanticipated density of the radar signals from ground radars. The cash outlay for NUSAT I was less than $\$ 20,000$ with more than $\$ 1$ million donated in the form of labor, parts, and services. This first satellite was the catalyst to organize the Center for Aerospace Technology (CAST) at Weber State University to help facilitate similar future endeavors.

NUSAT II was being developed while NUSAT I was still in orbit. The second satellite would have enhanced capabilities to complete the FAA experiments. The structure was space qualified and the electronic systems were prototyped before the shuttle disaster occurred. Work on NUSAT II was discontinued because of the loss of low cost launch opportunities.

Weber State University joined the Radio Amateur Satellite Team (AMSAT) to help build four microsat satellites. PACSAT(AO-16), DOVE(DO-17), WEBERSAT(WO-18), and LUSAT(LO-19) were launched into orbit in January of 1990, aboard an Ariane 4 from French Guiana. Each microsat weighs just 20 pounds and is less than a cubic foot in size. With five receivers, two transmitters, and 8 Megabytes of RAM storage, they are powerful communications satellites. Weber State University students built most of the flight hardware for all four microsats.

One of the four microsats was designated as WEBERSAT and carries an additional top module designed and built by students, local engineers, and faculty. The upper three inch module adds a CCD color camera, light spectrometer, particle impact sensor, and a microwave recelver. Daily contacts with WEBERSAT are convincing us that it is working very well. The learning process to effectively use the camera has taken months and we are still trying many of its variables.

The AMSAT Phase IV Satellite is yet another satellite that Weber State University has made significant contributions. The Phase IV is a 1000 pound satellite designed for a geostationary orbit. Weber students, local engineers, and faculty have contributed about 10,000 volunteer hours in building a full-scale model using the design by Dick Jansson. This project is temporarily on hold wafting for additional funding.

\section{ASTRONAUT DEPLOYABLE SATELLITE}

To continue our realistic engineering training at Weber state University, we needed another satellite project. The concept of an astronaut deployable satellite came about because of the prohibitive high costs of launching satellites. To launch again on the shuttle or the Ariane is now many times higher because of the commercial interest since our launches. The shuttle launch costs to eject a satellite from a Getaway Canister (GAS) is now beyond our budget capability. To reduce the launch interface expenses, maybe NASA could simply carry the satellite in a middeck stowage locker to altitude and then have an astronaut toss it into space. Negotiations with NASA have begun. They may never agree to the 
idea, but they have not said no either.

The ADSAT is being designed to send voice messages concerning onboard experiments. The voice messages will be generated by an onboard speech synthesizer that will verbally relay the data to low-cost scanners in schools throughout the world. With a low orbit of $150 \mathrm{miles}$ and the ADSAT transmitter power of 4 watts, communications to low-cost scanners is possible. The experiments carried aboard will be high school sponsored projects that will hopefully encourage space and science education.

The electronics design is being supervised by Dr. Robert Summers and Verne Hansen, both professors at Weber State University. They are advising senior projects teams in the design and testing of the microprocessor and its payload interfaces. Three students have completed the basic hardware design and three other students have begun the task of sof tware development. The ADSAT will have 32 channels for analog to digital conversion for sensors and experiments. A real-time clock will used to broadcast the time and to provide a time reference for the experiments. A speech and sound synthesizer will be used to generate the required audio sounds. A voltage controlled oscillator will be used to eransmit varying tones that will be tied to the experiments. A touch tone generator will be included to send down a specific sequence of tones to turn on ground stations. A CCD camera will be included to send back video images of the Earth.

A new technique to transmit video analog signals using audio signal paths is being designed by Professors Summers and Hansen. The video images taken by the satellite will be transmitted as FM modulated audio signals. The video data would then be received on the ground using a low cost scanner with the audio output going to an audio tape recorder. An interface card would allow the user to convert the tape recorded audio to video images on a standard personal computer with CGA graphics capability. The transmission of a single picture would only take a few minutes.

The signals will be transmitted to the ground using a 4 watt FM modulated audio signal using the amateur radio 2 Meter Band. The output power will be adjustable by the onboard computer as a tool to manage the power drain on the batteries. The solar panels and power regulator system should allow the transmitter to operate near full power while prolonging battery life and turning off unused circuits.

One of the experiments being designed uses a three-axis magnetometer and a voltage controlled oscillator to verbally tell the listeners how fast the satellite is tumbling in each axis. The output of each magnetometer will be fed into a voltage controlled oscillator that will change frequency as the satellite rotates. The speech synthesizer will take turns switching on each axis and transmit that audio tone for about ten seconds. Listeners on the ground could easily determine the satellites rate of tumble in each axis.

Other experiments might include a particle impact sensor, similar to the one now flying on WEBERSAT, an eclipse detector to determine the time the satellite is in the eclipse of the sun, and maybe even a photon light 
motor. The 32 analog input channels will allow some flexibility to fly some fun experiments. Power budget and volume allowed for each experiment will be the biggest limiting factor.

The speech synthesizer, sound generator, voltage controlled oscillator, and video audio will be programmed so that each has a turn transmitting data. The complete cycle of data will last about ten minutes and then continually repeat as the satellite orbits the Earth. The maximum reception time by any one ground receiver will be less than 10 minutes because of the low orbit.

The ADSAT space frame is about the size of a brief case measuring 16" $X 16^{\prime \prime} X 4^{\prime \prime}$ and will weigh less than 25 pounds. The mechanlcal design is complete and students in the Manufacturing Engineering Technology Department at Weber state University are about to begin building four ADSAT spaceframes. They will develop the processes to manufacture the frames using high technology concepts. Many parts will be machined on our fiveaxis Okuma Mill.

The ADSAT is designed to fit into a mid-deck stowage locker. When the astronaut desires to launch ADSAT, he opens the locker and pulls it out by the handle. The astronaut attaches ADSAT to the side wall of the shuttle using velcro to help facilitate exiting the pressure locks. The handle provides an easy grip for the astronaut as he releases the antenna. He Squeezes the trigger and the ADSAT gently springs out into space.

\section{CONCLUSION}

Satellite projects have provided students with an excellent vehicle to learn valuable englneering lessons. All of our departments are working together because the program would simply not survive without everyone contributing. Even if ADSAT never flies, the experiences and lessons learned will be Invaluable. Negotiations with NASA are underway and we are optimistic of flying in a couple of years. 